\title{
EVIDENCE FOR OSTEOCYTE-MEDIATED BONE-MATRIX DEGRADATION ASSOCIATED WITH PERIPROSTHETIC JOINT INFECTION (PJI)
}

\author{
R.T. Ormsby ${ }^{1}$, A.R. Zelmer ${ }^{1}$, D. Yang ${ }^{1}$, N.J. Gunn ${ }^{1}$, Y. Starczak ${ }^{1}$, S.P. Kidd ${ }^{2}$, R. Nelson ${ }^{3}$, L.B. Solomon ${ }^{1,4}$ \\ and G.J. Atkins ${ }^{1, *}$ \\ ${ }^{1}$ Centre for Orthopaedic and Trauma Research, The University of Adelaide, Adelaide, SA 5005, Australia \\ ${ }^{2}$ Australian Centre for Antimicrobial Resistance Ecology and Research Centre for Infectious Disease, \\ School of Molecular and Biomedical Science, The University of Adelaide, Adelaide, \\ South Australia, Australia \\ ${ }^{3}$ Department of Infectious Diseases, The Queen Elizabeth Hospital and Central Adelaide Local Health \\ Network, Woodville South, SA 5011, Australia \\ ${ }^{4}$ Orthopaedic and Trauma Service, Royal Adelaide Hospital and Central Adelaide Local Health Network, \\ Adelaide, SA 5000, Australia
}

\begin{abstract}
Osteomyelitis associated with periprosthetic joint infection (PJI) signals a chronic infection and the need for revision surgery. An osteomyelitic bone exhibits distinct morphological features, including evidence for osteolysis and an accelerated bone remodelling into poorly organised, poor-quality bone. In addition to immune cells, various bone cell-types have been implicated in the pathology. The present study sought to determine the types of bone-cell activities in human PJI bones. Acetabular biopsies from peri-implant bone from patients undergoing revision total hip replacement (THR) for chronic PJI (with several identified pathogens) as well as control bone from the same patients and from patients undergoing primary THR were analysed. Histological analysis confirmed that PJI bone presented increased osteoclastic activity compared to control bone. Analysis of osteocyte parameters showed no differences in osteocyte lacunar area between the acetabular bone taken from PJI patients or primary THR controls. Analysis of bone matrix composition using Masson's trichrome staining and second-harmonic generation microscopy revealed widespread lack of mature collagen, commonly surrounding osteocytes, in PJI bone. Increased expression of known collagenases, such as matrix metallopeptidase (MMP) 13, MMP1 and cathepsin K (CTSK), was measured in infected bone compared to non-infected bone. Human bone and cultured osteocyte-like cells experimentally exposed to Staphylococcus aureus exhibited strongly upregulated expression of MMP1, MMP3 and MMP13 compared to non-exposed controls. In conclusion, the study identified previously unrecognised bone-matrix changes in PJI caused by multiple organisms deriving from osteocytes. Histological examination of bone collagen composition may provide a useful adjunct diagnostic measure of PJI.
\end{abstract}

Keywords: Periprosthetic joint infection, osteomyelitis, osteocyte, osteoclast, osteocytic osteolysis, perilacunar remodelling, collagen, matrix metallopeptidase.

*Address for correspondence: Professor Gerald J. Atkins, Centre For Orthopaedic and Trauma Research, Faculty of Health and Medical Sciences, The University of Adelaide, North Terrace, Adelaide, SA, Australia, 5005.

Email: gerald.atkins@adelaide.edu.au

Copyright policy: This article is distributed in accordance with Creative Commons Attribution Licence (http://creativecommons.org/licenses/by-sa/4.0/).

\begin{tabular}{llll}
\hline & List of Abbreviations & Aur & aureolysin \\
& C. acnes & $\begin{array}{l}\text { Cutibacterium acnes } \\
\text { carbonic anhydrase 2 }\end{array}$ \\
$\alpha$-MEM & alpha-modification minimum & CA2 & colony-forming unit \\
& essential medium & CFU & computed tomography \\
ACET & acetabulum & CT & cycle threshold \\
ACTB & actin beta 1 & Ct & cathepsin G \\
ANOVA & analysis of variance & CTSG &
\end{tabular}




\begin{tabular}{|c|c|}
\hline CTSK & cathepsin K \\
\hline DMP1 & dentin matrix protein-1 \\
\hline EDTA & ethylenediaminetetraacetic acid \\
\hline FCS & foetal calf serum \\
\hline FGF23 & fibroblast growth factor- 23 \\
\hline GAPDH & $\begin{array}{l}\text { glyceraldehyde-3-phosphate } \\
\text { dehydrogenase }\end{array}$ \\
\hline HEPES & $\begin{array}{l}\text { 4-(2-hydroxyethyl)-1- } \\
\text { piperazineethanesulfonic acid }\end{array}$ \\
\hline IW & iliac wing \\
\hline MEPE & $\begin{array}{l}\text { matrix extracellular } \\
\text { phosphoglycoprotein }\end{array}$ \\
\hline MMP & matrix metallopeptidase \\
\hline MRI & magnetic resonance imaging \\
\hline MRSA & methicillin-resistant $S$. aureus \\
\hline MSSA & methicillin-sensitive $S$. aureus \\
\hline MSIS & Musculoskeletal Infection Society \\
\hline N.Ot/B.Ar & number of osteocytes per bone area \\
\hline OCN & osteocalcin \\
\hline Ot.Lac.Ar & osteocyte lacunar area \\
\hline Ot.Lac.Ar/B.Ar & osteocyte lacunar area per bone area \\
\hline P. aeruginosa & Pseudomonas aeruginosa \\
\hline PBS & phosphate-buffered saline \\
\hline PHEX & $\begin{array}{l}\text { phosphate regulating endopeptidase } \\
\text { homologue X-linked }\end{array}$ \\
\hline PJI & periprosthetic joint infection \\
\hline RANKL & $\begin{array}{l}\text { receptor activator of nuclear factor } \\
\text { kappa-B ligand }\end{array}$ \\
\hline RT-PCR & $\begin{array}{l}\text { reverse transcription polymerase } \\
\text { chain reaction }\end{array}$ \\
\hline S. aureus & Staphylococcus aureus \\
\hline S. warneri & Staphylococcus warneri \\
\hline SCV & small colony variants \\
\hline SHG & second-harmonic generation \\
\hline SOST & sclerostin \\
\hline SspB & staphopain B \\
\hline THR & total hip replacement \\
\hline TRAP & tartrate-resistant acid phosphatase \\
\hline TSB & tryptic soy broth \\
\hline
\end{tabular}

\section{Introduction}

The incidence of PJIs is underreported but is suggested to occur in 1-4 \% of primary surgeries (Ong et al., 2009) and, of concern, this rate is increasing (Web ref. 1). Infection rates increase to $3-15 \%$ when patients undergo revision surgery to replace a failed implant and this value increases with the number of revisions (Khan et al., 2019). PJI results in morbidities such as pain, poor mobility, prolonged hospitalisation and exposure to prolonged courses of broad-spectrum antimicrobial treatment. These infections can be extremely challenging to treat and often require repeated major surgeries. The number of cases where no viable reconstruction is possible is increasing. For example, the rate of above knee amputations for PJI of the knee more than tripled in the United States from 1998 to 2013 (George et al., 2018). The risk of in-hospital death after surgical admission for PJI is 2-fold higher than for aseptic revision surgery and PJI patients have a 5-fold increased mortality rate over non-infected implant recipients (Shahi et al., 2017). The economic burden of PJI is also considerable, with a recent study showing that treatment cost is at least 3 times that of the primary joint replacement, with double the hospital stay duration (Kapadia et al., 2016).

Despite the best efforts of clinicians, these infections frequently become chronic and may recur months or years after the initial infection appeared to have resolved. Antibiotic resistance of the infecting bacteria is a major and growing problem. Aggressive soft tissue and bone debridement is deemed necessary to cure these infections; however, this results in reduced muscle and bone tissue, which brings challenges to achieving prosthesis stability and restoring limb function. For treating PJI with an associated osteomyelitis, the standard of care is to perform a revision surgery, commonly performed in a staged manner. At the first stage, the infected implant is removed, the wound debrided and irrigated and a temporary implant coated with an antibioticladen cement inserted. Additionally, patients are administered high-dose systemic antibiotics for extended periods. After a variable time, when the infection is presumed cleared according to available criteria, the patient undergoes a second-stage surgery to replace the temporary implant with a permanent one.

PJI is currently diagnosed using a set of criteria, agreed to at the Second International Consensus Meeting on Musculoskeletal Infection (Parvizi et al., 2018), referred to as the MSIS criteria. Major criteria include the presence of a sinus tract communicating with the prosthesis or the isolation of the same organism from at least two soft tissue or fluid specimens from the patient. Routinely, intraoperative biopsies taken from soft tissue or joint capsule around the suspected infection site are examined by culture in both solid and broth media. Minor criteria include histology of frozen sections for the presence of at least 5 neutrophils/high-power field, elevated C-reactive protein, erythrocyte sedimentation rate, synovial fluid white-cell count and gross appearance. While the MSIS criteria are the gold standard for acute PJI, currently used markers are notoriously unreliable for detecting low level and/or persistent infections and, in particular, for detecting a residual infection during staged revision surgery (Anemuller et al., 2019). Thus, new diagnostic approaches are required for PJIs.

In addition to forming biofilm in a PJI, pathogens such as $S$. aureus have been shown to establish intracellular infections in several bone cell types, including osteoblasts (Ahmed et al., 2001; Tucker et al., 2000), macrophages, fibroblasts and osteoclasts. Internalised bacteria are able to induce cell death (Tucker et al., 2000) as well as form SCV that can reside for a long time, prolonging the infection, and potentially re-emerging later (Proctor et al., 2006).

Osteocytes, the most numerous and long-lived bone cell type, can become infected by $S$. aureus in PJI 
Table 1. PJI Patient demographics and pathogen identification. *Paired samples.

\begin{tabular}{|c|c|c|c|c|}
\hline PJI patient number & Gender & Age & Pathogen & Revision stage \\
\hline 1 & $\mathrm{M}$ & 46 & MRSA & Stage 1 \\
\hline 2 & $\mathrm{M}$ & 52 & Staphylococcus warneri & Stage 1 \\
\hline 3 & $\mathrm{M}$ & 56 & Staphylococcus warneri & Stage 1 \\
\hline 4 & $\mathrm{M}$ & 61 & MSSA & Stage 1 \\
\hline 5 & $\mathrm{M}$ & 66 & Staphylococcus warneri & Stage 1 \\
\hline 6 & $\mathrm{M}$ & 68 & Acinetobacter species & Stage 1 \\
\hline 7 & $\mathrm{M}$ & 75 & Cutibacterium acnes & Stage $1^{*}$ \\
\hline 8 & $\mathrm{M}$ & 89 & MRSA & Stage 1 \\
\hline 9 & $\mathrm{~F}$ & 53 & Culture-negative & Stage 1 \\
\hline 10 & $\mathrm{~F}$ & 61 & Staphylococcus epidermidis & Stage 1 \\
\hline 11 & $\mathrm{~F}$ & 61 & MRSA & Stage 1 \\
\hline 12 & $\mathrm{~F}$ & 88 & $\begin{array}{c}\text { Bacillus cereus } \\
\text { Citrobacter koseri }\end{array}$ & Stage 1 \\
\hline 13 & $\mathrm{~F}$ & 76 & Pseudomonas aeruginosa & Stage 1 \\
\hline 14 & $\mathrm{M}$ & 46 & MRSA & Stage 2 \\
\hline 15 & $\mathrm{M}$ & 70 & $\begin{array}{c}\text { Staphylococcus epidermidis } \\
\text { Gemella morbillorum }\end{array}$ & Stage 2 \\
\hline 16 & $\mathrm{M}$ & 70 & MSSA & Stage 2 \\
\hline 17 & $\mathrm{M}$ & 76 & Cutibacterium acnes & Stage $2^{*}$ \\
\hline 18 & $\mathrm{M}$ & 77 & MRSA & Stage 2 \\
\hline 19 & $\mathrm{~F}$ & 39 & MRSA & Stage 2 \\
\hline 20 & $\mathrm{~F}$ & 61 & Staphylococcus epidermidis & Stage 2 \\
\hline 21 & $\mathrm{~F}$ & 65 & $\begin{array}{l}\text { Staphylococcus pyogenes } \\
\text { Pseudomonas aeruginosa }\end{array}$ & Stage 2 \\
\hline 22 & $\mathrm{~F}$ & 67 & MSSA & Stage 2 \\
\hline \multirow{3}{*}{ Mean \pm SD } & $\mathrm{M}$ & $67.17 \pm 12.86$ & & \\
\hline & $\mathrm{F}$ & $63.44 \pm 13.69$ & & \\
\hline & All & $64.68 \pm 12.93$ & & \\
\hline
\end{tabular}

and, under experimental infections, transit to a SCV phenotype, suggesting that osteocytes may provide a long-term intracellular reservoir for a persistent infection (Yang et al., 2018). S. aureus has also been shown to reside within the canaliculi and empty lacunae of the lacunocanalicular system of infected bone (de Mesy Bentley et al., 2018; de Mesy Bentley et al., 2017). The osteocyte is a recognised major regulator of bone remodelling, critical in the control of osteoclastogenesis (O'Brien et al., 2013; Prideaux et al., 2016) and bone mineralisation (Atkins et al., 2011; Barragan-Adjemian et al., 2006). Importantly, the osteocyte itself can reversibly remove bone in the process of osteocytic osteolysis, also known as perilacunar remodelling, during lactation and weaning and in response to mechanical signals (Kogawa et al., 2018; Prideaux et al., 2016; Tsourdi et al., 2018). This occurs through the production of key bone-degrading enzymes including MMP13, CTSK and CA2 (Kogawa et al., 2013; Lotinun et al., 2019; Qing and Bonewald, 2009; Tang et al., 2012; Tsourdi et al., 2018). Furthermore, osteocytes have been shown to stimulate both osteoclastic resorption and osteocytic osteolysis, at least in female patients, in response to wear particles released from orthopaedic implants (Atkins et al., 2009; Ormsby et al., 2016; Ormsby et al., 2019a; Ormsby et al., 2019b). S. aureus has been shown to stimulate the expression of the proosteoclastogenic cytokine RANKL (Claro et al., 2011); however, there is an incomplete understanding of the effects of bacteria on bone remodelling, particularly in the context of an infected osteocyte. Therefore, the present study examined the histology of bone biopsies taken from patients with confirmed chronic PJI of the hip, from both the infected acetabular site and unaffected control bone from the IW as well as corresponding bone from patients undergoing primary THR. The effect of $S$. aureus on markers of bone destruction were also tested in ex vivo cultured human bone and in cultured osteocyte-like cells. Evidence for extensive collagenolysis was observed in PJI bone, commensurate with pathogen-induced expression of MMPs by osteocytes.

\section{Materials and Methods}

\section{Study participants}

Patients undergoing either primary THR surgery or revision THR surgery for a PJI, the latter group 
Table 2. Characteristics of primary THR patients.

\begin{tabular}{|c|c|c|}
\hline THR patient number & Gender & Age \\
\hline 21 & $\mathrm{M}$ & 40 \\
\hline 22 & $\mathrm{M}$ & 50 \\
\hline 23 & M & 52 \\
\hline 24 & $\mathrm{M}$ & 53 \\
\hline 25 & $\mathrm{M}$ & 54 \\
\hline 26 & $\mathrm{M}$ & 58 \\
\hline 27 & $M$ & 70 \\
\hline 28 & $\mathrm{M}$ & 70 \\
\hline 29 & $\mathrm{M}$ & 72 \\
\hline 30 & $\mathrm{M}$ & 75 \\
\hline 31 & $\mathrm{M}$ & 75 \\
\hline 32 & $\mathrm{M}$ & 76 \\
\hline 33 & $\mathrm{M}$ & 84 \\
\hline 34 & $\mathrm{~F}$ & 44 \\
\hline 35 & $\mathrm{~F}$ & 50 \\
\hline 36 & $\mathrm{~F}$ & 70 \\
\hline 37 & $\mathrm{~F}$ & 72 \\
\hline 38 & $\mathrm{~F}$ & 72 \\
\hline 39 & $\mathrm{~F}$ & 73 \\
\hline 40 & $\mathrm{~F}$ & 75 \\
\hline 41 & $\mathrm{~F}$ & 76 \\
\hline 42 & $\mathrm{~F}$ & 82 \\
\hline \multirow{3}{*}{ Mean age $\pm S D$} & $\mathrm{M}$ & $63.77 \pm 13.21$ \\
\hline & $\mathrm{F}$ & $68.22 \pm 42.03$ \\
\hline & All & $65.59 \pm 12.85$ \\
\hline
\end{tabular}

meeting the MSIS definition (Parvizi et al., 2018), were recruited at the Royal Adelaide Hospital after providing informed written consent and with ethical approval by the Human Research Ethics Committees of the Royal Adelaide Hospital and the University of Adelaide (RAH Approval No. 130114 and 140216a).

22 patients undergoing primary THR for osteoarthritis and 22 patients undergoing revision surgery for PJI were recruited. PJI patient demographics are listed in Table 1, including the identified pathogen(s) and the stage of revision. The single culture-negative patient had a sinus tract communicating with the prosthesis. Details of primary THR patients are listed in Table 2.

\section{Human bone biopsies}

Intraoperative bone trephine or curette biopsies of approximately $0.3-0.4 \mathrm{~g}$ wet weight were extracted from the peri-acetabular bone of primary THR patients, prior to insertion of the implant into the acetabular space, and from patients with confirmed PJI, after the removal of the implant. A core biopsy of the IW was also taken. Biopsies were washed thoroughly by vigorous shaking in $20 \mathrm{~mL}$ sterile PBS $(\mathrm{pH} 7.4)$ and discarding the supernatant, a process that was repeated 3 times. Then, biopsies were processed for RNA isolation and histology.

\section{RNA extraction and gene expression}

For RNA extraction from bone tissue, bone biopsies were frozen at $-80^{\circ} \mathrm{C}$ overnight. Then, the biopsies were placed in a mortar containing liquid nitrogen, pulverised to a powder using a pestle and approximately $0.2 \mathrm{~g}$ were immediately placed in $1 \mathrm{~mL}$ of TRIzol (Life Technologies). For RNA isolation from cultured cells, medium was removed and $1 \mathrm{~mL}$ TRIzol immediately added. RNA was extracted thereafter, as per the manufacturer's instructions. Complementary DNA was synthesised using iScript ${ }^{\mathrm{TM}}$ RT kit (Bio-Rad) and real time RTPCR was performed using RT2 SYBR Green Fluor qPCR Mastermix (Qiagen) on a CFX Connect Real Time PCR System (Bio-Rad). Gene expression was normalised to that of the housekeeping genes GAPDH or $A C T B$, as indicated, whose levels remained constant relative to the total concentration of RNA used for the reverse transcription reaction. Relative gene expression in patient samples was calculated using the delta-Ct method: $2^{-\Delta \mathrm{Ct}}$, where $\Delta \mathrm{Ct}=\mathrm{Ct}$ of gene of interest $-\mathrm{Ct}$ of the housekeeping gene. For infection experiments, gene expression was expressed as fold-change and calculated using the delta-deltaCt $\left(2^{-\Delta C t}\right)$ method (Livak and Schmittgen, 2001). Oligonucleotide primer sequences are listed in Table 3. All primers were designed in-house and purchased from Sigma-Aldrich.

\section{Histological analysis of human bone biopsies}

For histology, bone biopsies were fixed in $10 \%$ neutral-buffered formalin for $48 \mathrm{~h}$ and then decalcified (10 \% EDTA/1 \% paraformaldehyde) for 2 weeks. Decalcification was checked by $X$-ray scanning (Faxitron, Tucson, AZ, USA). Following embedding in paraffin-wax, sections $(5 \mu \mathrm{m})$ were cut and stained for histology and histochemistry. Alternatively, bone biopsies from some patients were embedded in Tissue-Tek ${ }^{\circledR}$ O.C.T. Compound (Sakura Finetek, Tokyo, Japan) and frozen for sectioning using a cryostat.

\section{TRAP}

For osteoclast analysis, sections were stained for TRAP activity using a modified resin-embedded sections protocol (Ryan et al., 2016). Sodium nitrite solution $(4 \% \mathrm{w} / \mathrm{v})$ was added in a 50:50 volume ratio to basic fuchsin. A $0.2 \mathrm{~mL}$ aliquot of this solution was added to $35 \mathrm{~mL}$ of a solution of tartaric acid $(0.1 \%$ $\mathrm{w} / \mathrm{v})$ dissolved in sodium acetate $(10 \mathrm{mmol} / \mathrm{L}, \mathrm{pH} 5.2)$. Then, $2 \mathrm{~mL}$ of Napthol ASBI phosphate $(2 \% \mathrm{w} / \mathrm{v}$; Sigma-Aldrich) in dimethyl formamide was added. Bone sections $(5 \mu \mathrm{m})$ on microscope slides (prepared as described above) were placed in this solution, upright in a Coplin jar, and incubated for $60 \mathrm{~min}$ at $37^{\circ} \mathrm{C}$ in the dark. Then, samples were counterstained with toluidine blue (as described below), rinsed and dipped briefly into saturated lithium carbonate solution. Samples were dehydrated in a $50-90 \%$ ethanol series $(50 \%, 70 \%, 90 \%$ ethanol, 
Table 3. Real-time RT-PCR primers used. F: forward. R: reverse.

\begin{tabular}{|c|c|c|c|}
\hline Gene & Direction & Primer sequences $\left(5^{\prime}-3^{\prime}\right)$ & Reference \\
\hline$A C T B$ & $\begin{array}{l}\mathrm{F} \\
\mathrm{R}\end{array}$ & $\begin{array}{c}\text { CGCGAGAAGATGACCCAGATC } \\
\text { TCACCGGAGTCCATCACG }\end{array}$ & Ormsby et al., 2016 \\
\hline$C A 2$ & $\begin{array}{l}\mathrm{F} \\
\mathrm{R}\end{array}$ & $\begin{array}{l}\text { TCTCAGGACAAAGCAGTGCTCA } \\
\text { GAACCAAGTGAAGTTCTGCAGC }\end{array}$ & Kogawa et al., 2010 \\
\hline CTSK & $\begin{array}{l}\mathrm{F} \\
\mathrm{R}\end{array}$ & $\begin{array}{c}\text { GGCCAACTCAAGAAGAAAACTG } \\
\text { TCTCTGTACCCTCTGCATTTAGC }\end{array}$ & Kogawa et al., 2010 \\
\hline GAPDH & $\begin{array}{l}\mathrm{F} \\
\mathrm{R}\end{array}$ & $\begin{array}{c}\text { ACCCAGAAGACTGTGGATGG } \\
\text { CAGTGAGCTTCCCGTTCAG }\end{array}$ & Atkins et al., 2007 \\
\hline$D M P 1$ & $\begin{array}{l}\mathrm{F} \\
\mathrm{R}\end{array}$ & $\begin{array}{l}\text { GATCAGCATCCTGCTCATGTT } \\
\text { AGCCAAATGACCСTTCCATTC }\end{array}$ & Atkins et al., 2009 \\
\hline FGF23 & $\begin{array}{l}\mathrm{F} \\
\mathrm{R}\end{array}$ & $\begin{array}{l}\text { ATGCTGGCTTTGTGGTGATTA } \\
\text { TCTCCGGGTCGAAATAGTGT }\end{array}$ & Ito et al., 2015 \\
\hline$M E P E$ & $\begin{array}{l}\mathrm{F} \\
\mathrm{R}\end{array}$ & $\begin{array}{c}\text { AGATTCTCAAAGATGCGAGTTTTC } \\
\text { CCTCTGCTCTTCCACACAGC }\end{array}$ & \\
\hline$M M P 1$ & $\begin{array}{l}\mathrm{F} \\
\mathrm{R}\end{array}$ & $\begin{array}{l}\text { AAACACATCTGACCTACAGGA } \\
\text { TTACTCCAGAGTTGGAAGGC }\end{array}$ & \\
\hline MMP3 & $\begin{array}{l}\mathrm{F} \\
\mathrm{R}\end{array}$ & $\begin{array}{l}\text { GTAGAGGACAAATACTGGAGA } \\
\text { CAGTAAAGAAATAAAAGAACCC }\end{array}$ & \\
\hline MMP13 & $\begin{array}{l}\mathrm{F} \\
\mathrm{R}\end{array}$ & $\begin{array}{l}\text { GGATCCAGTCTCTCTATGGT } \\
\text { GGCATCAAGGGATAAGGAAG }\end{array}$ & Ormsby et al., 2016 \\
\hline OCN & $\begin{array}{l}\mathrm{F} \\
\mathrm{R}\end{array}$ & $\begin{array}{l}\text { ATGAGAGCCCTCACACTCCTCG } \\
\text { GTCAGCCAACTCGTCACAGTCC }\end{array}$ & Atkins et al., 2007 \\
\hline PHEX & $\begin{array}{l}\mathrm{F} \\
\mathrm{R}\end{array}$ & $\begin{array}{c}\text { CATCCAATGAACATATCTTGAAGC } \\
\text { ACTTGTAAAGGGCATCCCGATAA }\end{array}$ & Atkins et al., 2011 \\
\hline RANKL & $\begin{array}{l}\mathrm{F} \\
\mathrm{R}\end{array}$ & $\begin{array}{c}\text { TCAGCCTTTTGCTCATCTCACTAT } \\
\text { CCACCCCCGATCATGGT }\end{array}$ & Atkins et al., 2007 \\
\hline SOST & $\begin{array}{l}\mathrm{F} \\
\mathrm{R}\end{array}$ & $\begin{array}{c}\text { ACCGGAGCTGGAGAACAACA } \\
\text { GCTGTACTCGGACACGTCTT }\end{array}$ & Atkins et al., 2009 \\
\hline
\end{tabular}

each 15 s). Following, sections were dipped 20 times into absolute ethanol and, then, cleared by adding a drop of xylene and incubating for 2 min; this step was repeated a total of 3 times. Finally, samples were mounted using DPX mounting medium (SigmaAldrich). Sections were imaged using a NanoZoomer (Hamamatsu Photonics). Osteoclasts, in blinded sections, were identified as TRAP-positive (magenta/ red) and counted; total bone area was quantified by using the Freehand region measurement tool in the NanoZoomer software (Hamamatsu Photonics) with manual tracing using the Bamboo Pen and Touch (Wacom, Kazo, Saitama, Japan).

\section{Toluidine blue}

Bone sections were also stained with toluidine blue for Ot.Lac.Ar analysis, as previously described (Ormsby et al., 2016). Briefly, bone sections were stained with toluidine blue O (1\% w/v; Sigma-Aldrich) in $70 \%$ ethanol for $3 \mathrm{~min}$. After washing 3 times in distilled water, samples were dehydrated in ethanol, cleared in xylene (Sigma-Aldrich), mounted and imaged, as for TRAP staining. From the NanoZoomer images, areas of all identifiable osteocyte lacunae were quantified in each trabecula of the biopsy by manual tracing by a blinded operator. This generated data for the Ot.Lac.Ar, Ot.Lac.Ar/B.Ar and N.Ot/B.Ar. This was performed for both acetabular biopsies and control IW biopsies. A similar analysis was conducted for the acetabular bone biopsies from patients undergoing primary THR.

\section{SHG microscopy}

SHG microscopy (Campagnola et al., 2002; Nadiarnykh et al., 2007) was used to determine the fibrillary structure of the collagen in the bone and displayed changes in the infected bone biopsies where the normal lamellar structures were disrupted. Briefly, bone sections were visualised using the Leica SP8 Multiphoton Confocal System by utilising lowenergy infrared laser light using a 20× objective lens.

\section{Masson's trichrome}

Bone matrix composition was examined using Masson's trichrome staining (Ponce et al., 2018). The principle of this staining is that two dyes bind to the different formations of collagen in normal bone: aniline blue binds to the non-mineralised osteoid, an immature collagen matrix, whereas Biebrich scarlet-acid fuchsin red stains the mature collagen fibrils of the bone. For this, sections were dewaxed in neat xylene for $2 \mathrm{~min}$, then washed sequentially for 2 min each in absolute ethanol, $90 \%$ ethanol, $70 \%$ ethanol and then running water. Next, sections were stained using Mayer's iron haematoxylin working solution for $5 \mathrm{~min}$, washed with distilled water for $2 \mathrm{~min}$, then stained using Biebrich scarlet-acid fuchsin $(1 \% \mathrm{w} / \mathrm{v})$ solution for $5 \mathrm{~min}$. After washing 
in distilled water (2 min), sections were immersed in phosphomolybdic-phosphotungstic acid solution $(2.5 \% \mathrm{w} / \mathrm{v}$ each) for $5 \mathrm{~min}$. Sections were transferred without rinsing to aniline blue solution ( $3 \% \mathrm{w} / \mathrm{v}$ aniline blue, $2 \% \mathrm{v} / \mathrm{v}$ acetic acid in distilled water) and stained for $5 \mathrm{~min}$. Sections were differentiated in $1 \% \mathrm{v} / \mathrm{v}$ acetic acid solution for $5 \mathrm{~min}$. After brief rinsing in water, sections were rapidly dehydrated, cleared in xylene, mounted and imaged, as described above for TRAP staining.

For blinded quantification of Masson's trichrome staining, images of at least 2 samples per patient (Table 1,2), who had undergone either primary THR, first-stage revision for PJI or second-stage revision for PJI, were analysed using Fiji (ImageJ 2) software. Areas of the images that showed tissues other than bone were removed and the image colours split using the Masson's trichrome deconvolution function into red and blue. The thresholds were adjusted to include the whole bone in the deconvoluted blue image and only the area of red/purple staining in the deconvoluted red image. Percentages of the different colour stainings were analysed using GraphPrism 9.0.0, ANOVA and a Brown-Forsythe and Welch test.

\section{Human MMP13 antibody immunofluorescence assay}

For the purposes of immunostaining, some biopsies were fixed and decalcified in TheraLin ${ }^{\mathrm{TM}}$ tissue fixative (Grace Bio-Labs, Bend, OR, USA) at room temperature for $48 \mathrm{~h}$ (Yang et al., 2018). Next, biopsies were embedded in Tissue-Tek O.C.T. compound (ProSciTech) and frozen at $-80^{\circ} \mathrm{C}$ overnight. Biopsies were sectioned using a cryostat $(20 \mu \mathrm{m})$ and stored at $-20^{\circ} \mathrm{C}$. To detect MMP13, sections were blocked using $5 \% \mathrm{v} / \mathrm{v}$ normal rabbit serum in PBS for $30 \mathrm{~min}$, washed with wash buffer $(0.5 \% \mathrm{v} / \mathrm{v}$ normal rabbit serum in PBS) 3 times and incubated with either antihuman MMP13 primary antibody (MAB511; 1:500, R\&D Systems) or isotype-matched negative control monoclonal antibody (MAB002, R\&D Systems) in a dark humidified chamber for $1.5 \mathrm{~h}$. Then, sections were washed (wash buffer, 3 times) and incubated with the secondary antibody AlexaFluor 647 (1:1000 dilution; A-21239, Life Technologies) for $1.5 \mathrm{~h}$ in a dark, humidified chamber. Samples were mounted using Fluorescence Mounting Medium (Agilent Technologies). Immunofluorescence was detected using an Olympus FV3000 confocal microscope using a $20 \times$ objective lens.

\section{Ex vivo bone infection assay}

An ex vivo human bone infection assay was performed, essentially as previously described (Hofstee et al., 2020; Yang et al., 2018). Briefly, cancellous bone from the proximal femur was collected from patients undergoing total hip arthroplasty. Bone biopsies were dissected into approximately $1 \mathrm{~mm}^{3}$ pieces in sterile PBS and agitated using a laboratory vortex 6 times, each time in fresh PBS, to remove any remaining blood and loosely adherent tissue. Approximately
20 such bone pieces were placed each into $50 \mathrm{~mL}$ sterile tube with $25 \mathrm{~mL}$ of antibiotic and serum-free $\alpha$-MEM (Gibco). A MRSA strain WCH-SK2 (Bui et al., 2015) was cultured in TSB (Thermo Fisher Scientific) until log-phase growth was reached and the CFU/ $\mathrm{mL}$ calculated using optical density measurement at $600 \mathrm{~nm}$. Bacteria were pelleted by centrifugation for $5 \mathrm{~min}$ at 4,000 $\times g$ and resuspended in PBS to $10^{5} \mathrm{CFU} /$ $\mathrm{mL}$. Then, $1 \times 10^{3} \mathrm{CFU}$ were added per $1 \mathrm{~mm}^{3}$ bone piece. Next, tubes were placed in a $37^{\circ} \mathrm{C}$ shaking incubator and cultured with gentle agitation for 12 h. Following this, total RNA was extracted, as described above.

\section{In vitro osteocyte infection assay}

Cancellous bone from the proximal femur, collected from patients undergoing total hip arthroplasty, was processed into small $1 \mathrm{~mm}^{3}$ bone chips, washed extensively with sterile PBS and cultured in $\alpha \mathrm{MEM}$ (Life Technologies) containing $10 \%$ v/v FCS (ThermoFisher Scientific) in T75 tissue culture flasks, allowing cells to grow out on to the tissue culture plastic. Medium was changed every $3 \mathrm{~d}$ for a period of 3 weeks for cells to reach confluence, at which point they were resuspended by digestion with $1 \mathrm{mg} /$ $\mathrm{mL}$ collagenase (Sigma-Aldrich) for $1 \mathrm{~h}$ followed by $0.05 \%$ trypsin/EDTA solution for $5 \mathrm{~min}$. At this point, cells were either cryopreserved as primary osteoblasts or seeded into 12-well tissue culture plates at $1 \times 10^{5}$ cells/well and cultured at $37^{\circ} \mathrm{C}$ and $5 \% \mathrm{CO}_{2}$ in differentiation medium consisting of $\alpha \mathrm{MEM}$ (Life Technologies), $5 \% \mathrm{v} / \mathrm{v}$ FCS, $1.8 \mathrm{mmol} / \mathrm{L}$ potassium dihydrogen phosphate (Sigma-Aldrich), $100 \mu \mathrm{mol} / \mathrm{L}$ ascorbate-2-phosphate (Sigma-Aldrich) and standard tissue culture additives (10 mmol/L HEPES, $2 \mathrm{mmol} / \mathrm{L}$ L-glutamine, penicillin/streptomycin each 1 unit/mL, Thermo-Fisher). Following a 4-week differentiation period under these conditions, these cells display an osteocyte-like phenotype characterised by localised mineral deposition and high levels of expression of osteocyte markers including SOST, DMP1, MEPE and PHEX (Atkins et al., 2011; Welldon et al., 2013; Wijenayaka et al., 2011; Yang et al., 2018). Infection of osteocyte-like cultures with $S$. aureus strain WCHSK2 was performed, as described previously (Yang et al., 2018). Briefly, a log-phase culture of WCH-SK2, generated as above, was diluted in PBS to a stock concentration of $5 \times 10^{9} \mathrm{CFU} / \mathrm{mL}$ and, then, used to inoculate the differentiated cells at either $1 \times 10^{7}$, $5 \times 10^{7}$ or $1 \times 10^{8} \mathrm{CFU} /$ well. After $2 \mathrm{~h}$, medium was replaced with antibiotic-free differentiation medium containing $20 \mu \mathrm{g} / \mathrm{mL}$ lysostaphin (Sigma-Aldrich) to remove residual extracellular bacteria. After $24 \mathrm{~h}$, cultures were processed for total RNA isolation and RT-PCR, as described above.

\section{Statistical analysis}

All statistical analyses were performed using GraphPad Prism software. Differences in osteoclast histological measures were analysed using MannWhitney test. Differences in osteocyte measures were 
tested using one-way ANOVA with Tukey's post-hoc test. Differences in gene expression between iliac and acetabular samples was analysed using the nonparametric Wilcoxon signed rank test. Differences in gene expression in response to in vitro infection were analysed using one-way ANOVA with Dunnett's multiple comparisons test. In all cases, a value for $p<0.05$ was considered statistically significant.

\section{Results}

\section{Patient demographics}

Peri-implant acetabular bone biopsies and IW controls were obtained from 22 patients, 13 males and 9 females, undergoing revision THR for PJI. Patient ages, gender, microorganisms and revision THR stage are listed in Table 1.16 of the 22 cases of PJI involved Staphylococcal species, with $S$. aureus in 9 cases, including 6 MRSA strains. 7 patients presented coagulase-negative Staphylococcal strains. 2 samples were from 1 individual with $C$. acnes. 2 patients had sole Gram-negative PJIs, $1 P$. aeruginosa, 1 Acinetobacter. 3 patients had confirmed polymicrobial infections and 1 was culture-negative.

Control acetabular biopsies were also obtained from 22 patients, 13 males and 9 females, undergoing primary THR surgery. The mean age of this group was $65.59 \pm 12.85$ years, which was not significantly different from the PJI group $(64.68 \pm 12.93$ years; $p=0.81)$. Individual characteristics of this group are listed in Table 2.

\section{Osteoclast measures}

To examine pathological cellular processes evident in acetabular bone from the PJI group, TRAP activity was measured by histochemical analysis, being the most widely used marker of active bone-resorbing a

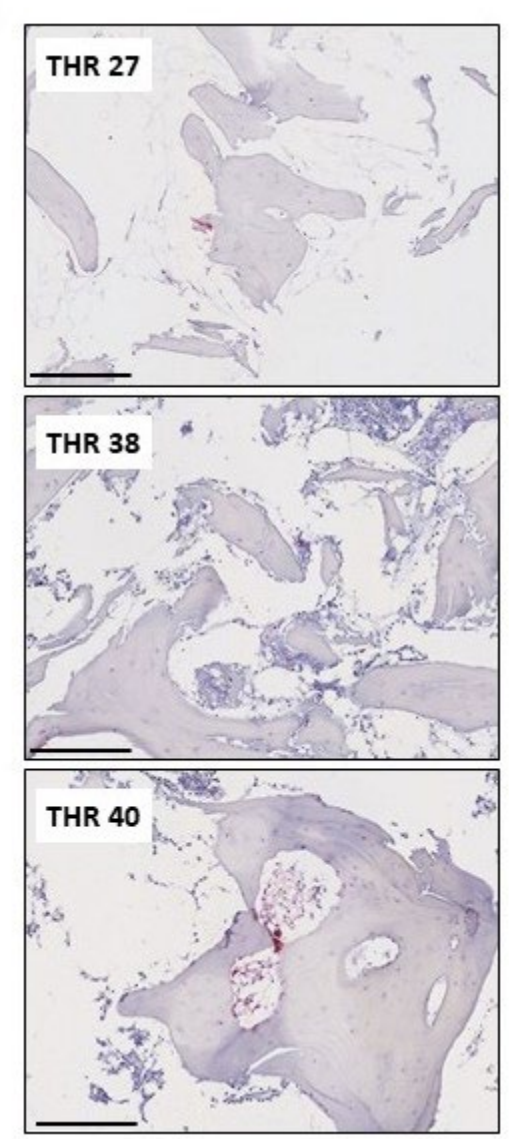

PRIMARYTHR

C

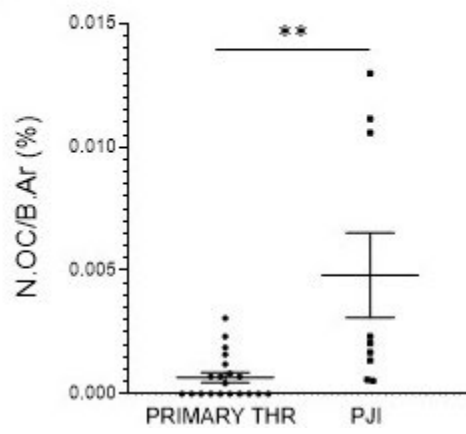

b
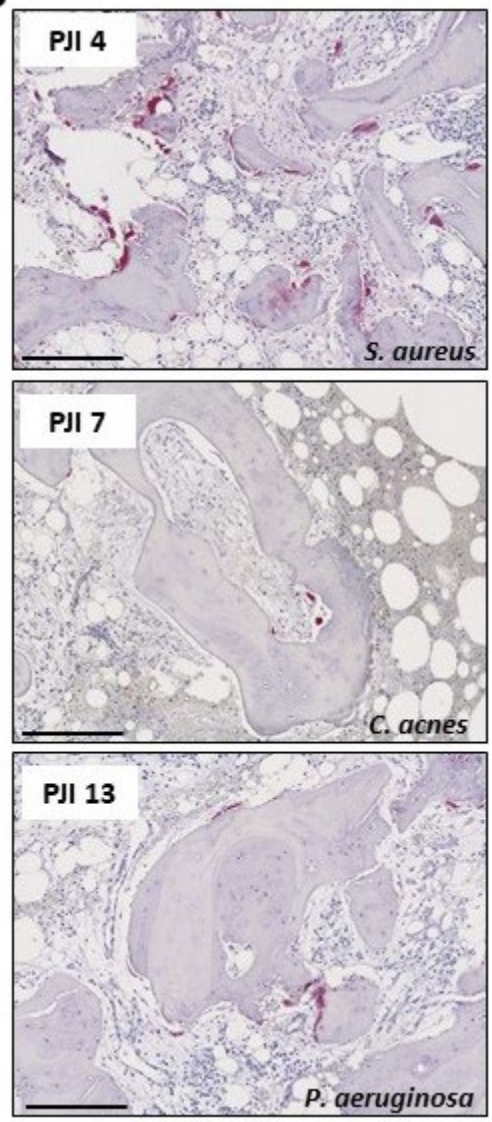

PJI

Fig. 1. TRAP-positive osteoclast activity in PJI bone. Cancellous bone samples taken from the ACET of (a) patients undergoing primary THR surgery or (b) revision THR surgery for PJI were embedded, sectioned and stained for TRAP. Representative images from patients of each cohort are shown, with numbers corresponding to patients listed in Table 1,2. Organisms identified are indicated. Scale bars: $250 \mu \mathrm{m}$. (c) N.Oc/B.Ar was measured for 19 THR and 10 PJI patients. Data shown are mean values for at least 3 sections/patient sample. Significant difference, determined by Mann-Whitney test, two-way, is indicated by ${ }^{* *} p<0.01$. 
osteoclasts. Control acetabular biopsies taken from patients undergoing primary THR exhibited low numbers of bone-surface-associated TRAP-positive cells (Fig. 1a). TRAP staining of PJI bone revealed relatively elevated osteoclast numbers per bone area (Fig. 1b-c), confirming elevated osteoclastic bone turnover in PJI.

\section{Osteocyte measures}

Analysis of toluidine-blue-stained sections revealed no difference in Ot.Lac.Ar between PJI and primary THR bone or between the IW control and acetabular specimens for each group (Fig. 2a). Since a genderspecific effect on this measure has been previously reported in patients undergoing THR surgery for aseptic loosening (Ormsby et al., 2019a), males and females were also analysed separately. However, Ot.Lac.Ar was unchanged by either site or infection status in both sexes. Analysis of N.Ot/B.Ar revealed an increased osteocyte density in acetabular bone compared to IW and this effect was driven by the effect in females (Fig. 2b). Interestingly, this measure was relatively increased in acetabular bone samples from PJI patients compared with controls, indicative of increased bone remodelling in infected bone. This relationship only existed in males. The related measure of Ot.Lac.Ar relative to Ot.Lac.Ar/B.Ar was also increased in ACET over IW and was significantly greater in PJI ACET over primary THR bone (Fig. 2c).

\section{Bone matrix integrity in PJI bone}

Bone matrix integrity was examined in the two patient cohorts. For this purpose, first Masson's trichrome was used to distinguish between mature collagen fibrils and immature collagen matrix, for example in the case of non-mineralised osteoid. a

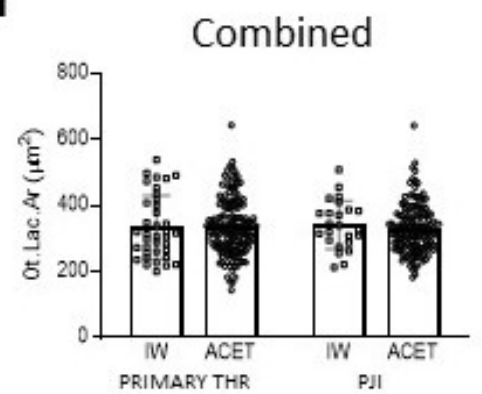

b

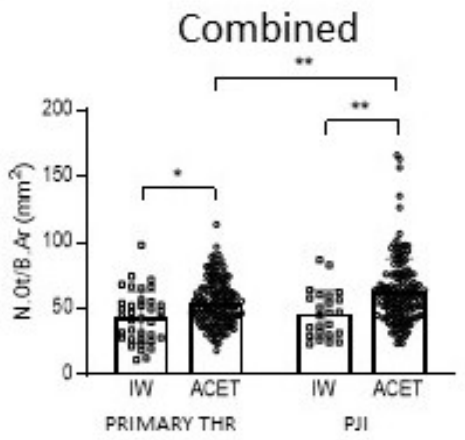

C

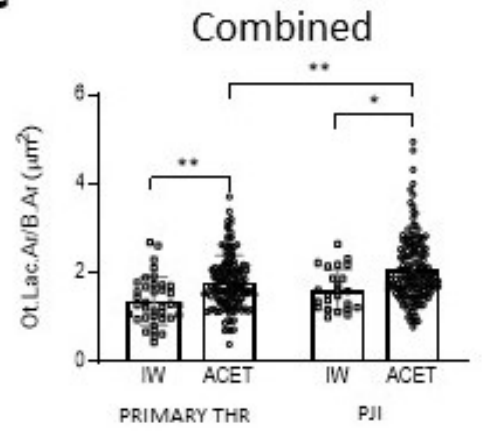

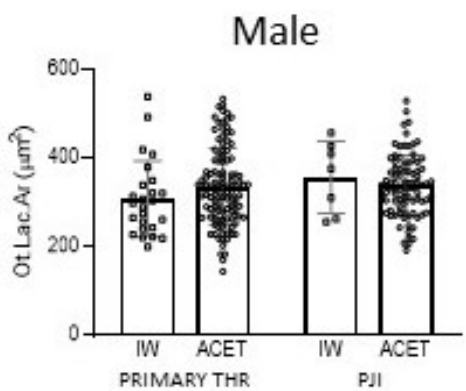

Male

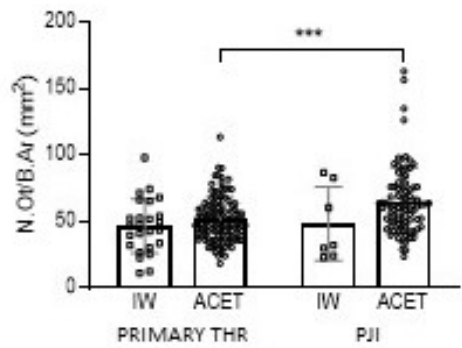

Male

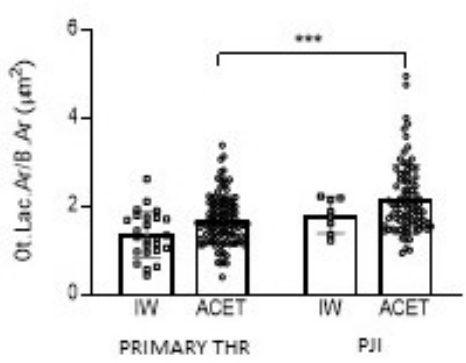

Female

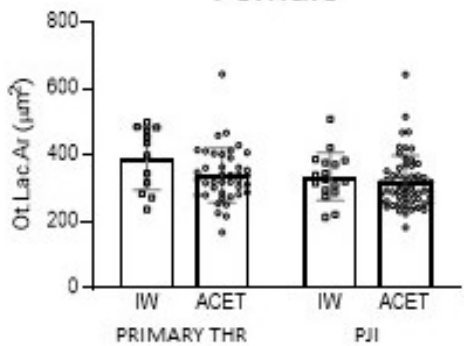

Female

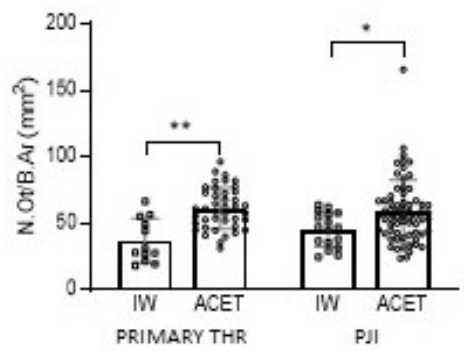

Female

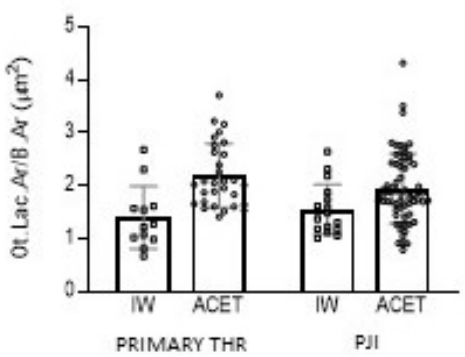

Fig. 2. Osteocyte measures in primary THR and PJI bone. Histomorphometric measures of (a) Ot.Lac.Ar, (b) N.Ot/B.Ar and (c) Ot.Lac.Ar/B.Ar were made of paired IW and acetabular bone biopsies taken from patients either undergoing primary THR or staged revision surgery for PJI. Comparisons were made between the IW and ACET within each cohort and corresponding sites between cohorts. Significance, determined by paired (between sites within each cohort) or unpaired Student's $t$-test, two-way, is indicated by ${ }^{*} p<0.05$, ${ }^{* *} p<0.01,{ }^{* * *} p<0.001$. 
Primary THR bone was stained as a uniform mature collagen matrix, staining magenta, with peripheral blue zones, indicating osteoid seams (Fig. 3a). However, PJI bone presented extensive, apparently immature or degraded collagen within trabeculae encompassing numerous osteocyte lacunae and was evident in patients with either Gram-positive (Fig. 3b) or Gram-negative (Fig. 3c) PJIs. Such a staining pattern was evident in biopsies taken from all patients undergoing either first-stage (Fig. 3b) or second-stage

a
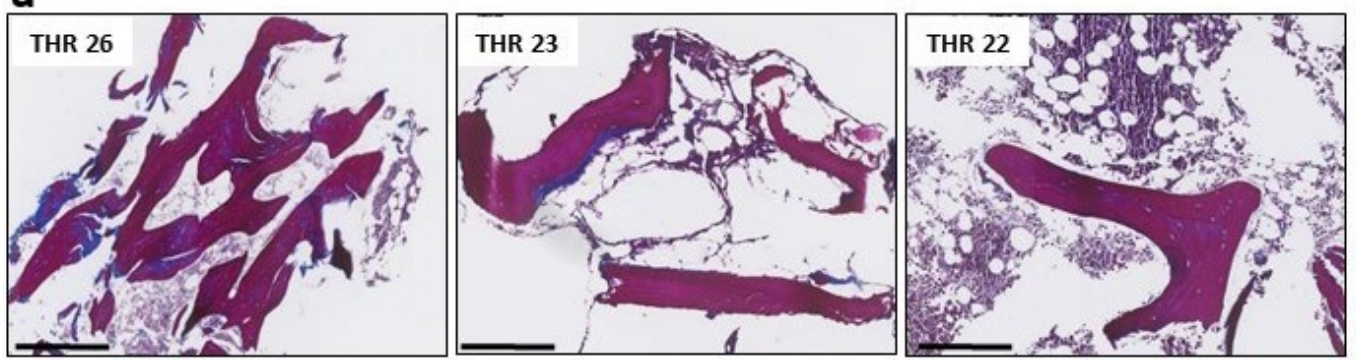

b
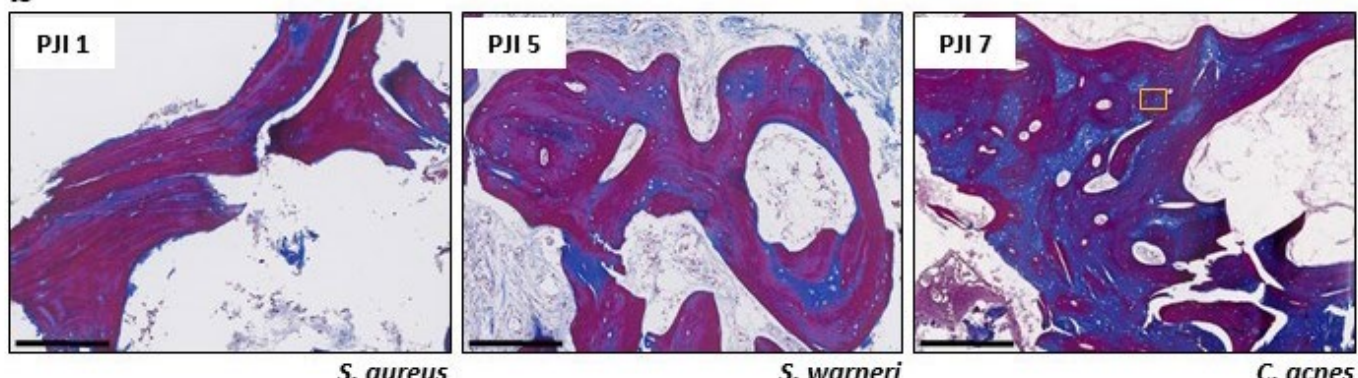

c

\section{d}
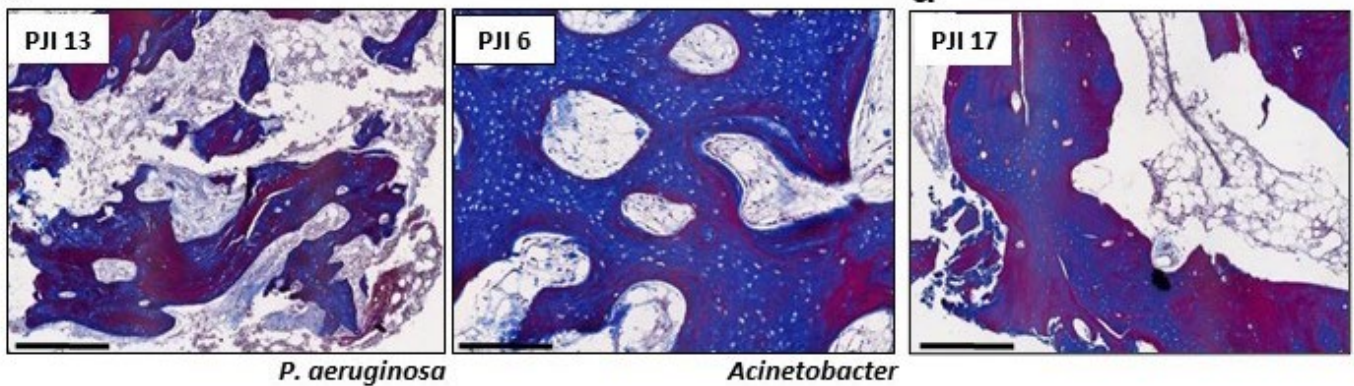

Acinetobacter
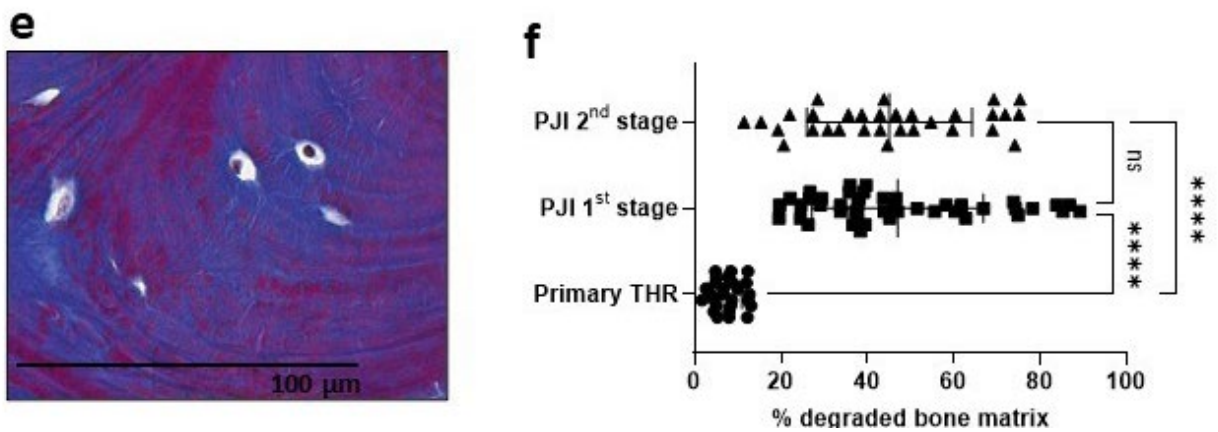

Fig. 3. Histological analysis of type I collagenous bone matrix organisation. Masson's trichrome staining was performed on acetabular bone biopsies taken from patients either undergoing primary THR or staged revision surgery for PJI. Examples are shown of (a) primary THR, (b) PJI patients undergoing first-stage revision with a Gram-positive organism (indicated), (c) PJI patients undergoing first-stage revision with a Gram-negative organism (indicated). (d) Staining of a sample from a patient (PJI 17) undergoing secondstage revision, corresponding to patient PJI 7 in b. (a-d) Scale bars: $500 \mu \mathrm{m}$. (e) Increased magnification of PJI 7 showing loss of mature collagen surrounding embedded osteocytes contiguous with lamellar collagen fibrils (corresponding approximately to the region in the yellow rectangle in $\mathbf{b}$ ). (f) Quantification expressed as percentage degraded bone matrix corresponds to intra-trabecular areas stained blue as a percentage of the total bone area. At least two stained tissue sections each of patient samples from cases of primary THR $(n=13)$ or those undergoing first- $(n=12)$ or second- $(n=9)$ stage revision of PJI of the hip $($ Table 1,2$)$ were measured. Significant differences were tested by Brown-Forsythe and Welch ANOVA multiple comparisons test and are indicated by ${ }^{* * *} p<0.0001$ and ns (not significant). 
(Fig. 3d) surgeries. In many cases, organised lamellar structures were evident within the apparently immature collagen zone (Fig. 3e), suggesting that degradation or remodelling of mature collagen occurred in these samples around the resident osteocytes rather than the areas representing woven bone. Regions of woven bone were also evident, characterised by circular osteocyte lacunae in a poorly organised matrix, for example as seen for PJI 6 (Fig. 3c). Quantification of Masson's trichrome staining revealed that PJI cases at either the first or second stage of their revision treatment had significantly more apparently degraded bone matrix than primary THR cases (both $p<0.0001$, Fig. 3f).

To further examine collagen structure, SHG analysis was performed, which to the authors' knowledge is the first application of this technology to either PJI or osteomyelitis in general. Primary THR bone exhibited the expected uniform pattern of aligned and intact, purple fluorescent collagen fibrils, with peripheral zones lacking such fibrils consistent with surface osteoid (Fig. 4a). PJI bone exhibited large intra-trabecular zones surrounding osteocyte lacunae where loss of mature collagen fibrils was apparent, indicative of immature or degraded collagen (grey zones; Fig. 4b).

\section{Gene expression in PJI bone}

To investigate host factors that may explain the effects on bone matrix organisation and degradation in PJI, gene expression of known collagenases was examined in patient samples. PJI samples showed significantly increased expression of MMP family members, MMP13 (Fig. 5a) and MMP1 (Fig. 5b), in acetabular biopsies, compared to IW bone distal from the infected site taken from the same patient. Similarly, a trend for increased expression of CTSK was observed in the acetabular biopsies compared to IW control (Fig. 5c). Levels of CA2, a gene associated with osteocytic osteolysis as well as osteoclastic bone resorption (Kogawa et al., 2013), were unchanged in PJI biopsies (Fig. 5d). a
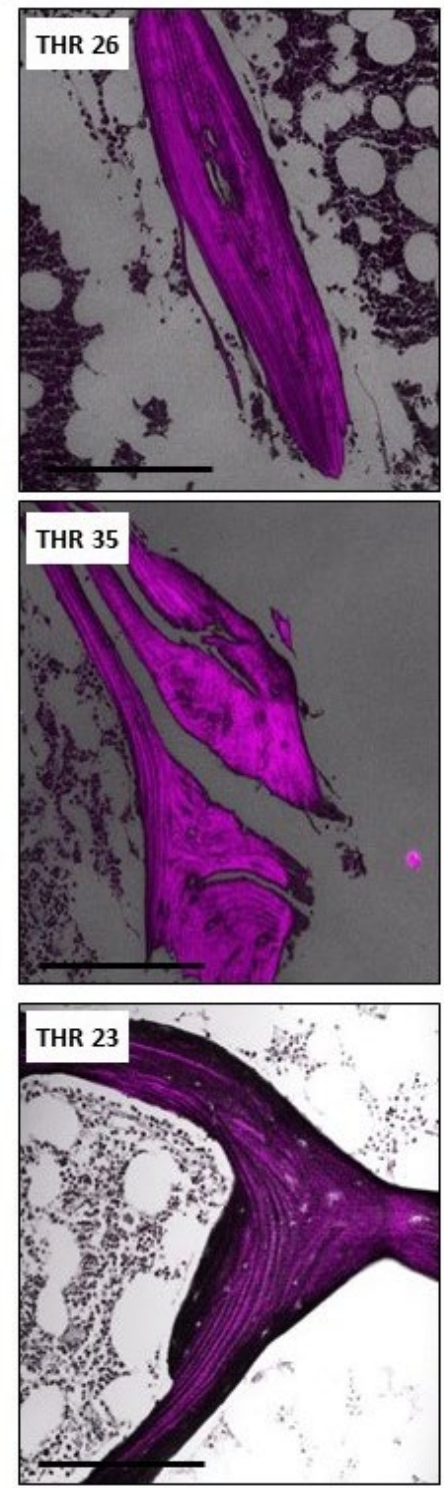

Primary THR b
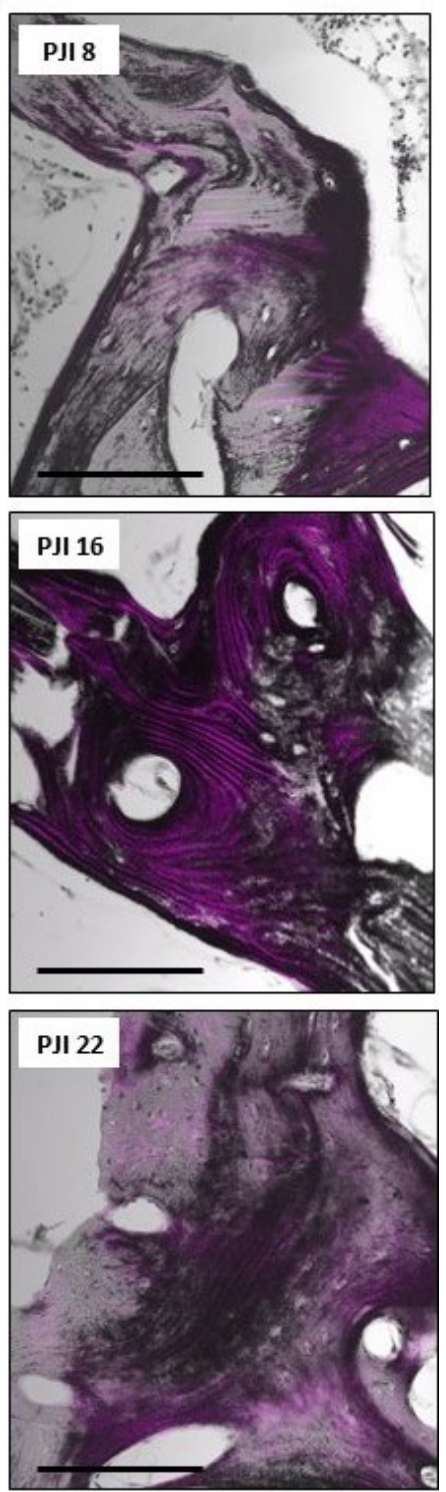

PJI
Fig. 4. Analysis of type I collagen fibrillar structure. Sections of the ACET of (a) patients undergoing primary THR surgery or (b) revision THR surgery for PJI were embedded, sectioned and examined by SHG analysis. Representative images from patients of each cohort are shown, with numbers corresponding to patients listed in Table 1,2. S. aureus was the infective organism in all PJI cases. Scale bars: $200 \mu \mathrm{m}$. 
Immunofluorescence for MMP13 expression in primary and PJI bone biopsies

Immunofluorescent staining for MMP13, a metalloproteinase associated with osteocytic osteolysis (Tang et al., 2012), was performed on 20 umthick sections from OCT (ProSciTech)-embedded PJI and primary THR bone biopsies. MMP13 staining was evident in some osteocyte lacunae in the primary THR bone, as expected (Fig. 6). In PJI bone, intense staining for MMP13 was evident in osteocyte lacunae and also throughout the bone matrix (Fig. 6).

\section{Ex vivo bone infection analysis}

To examine whether bone-matrix-degrading enzymes were expressed due to infection, ex vivo bone infection experiments were performed based on a previously described model (Yang et al., 2018). Bone pieces from a primary THR patient were exposed to $S$. aureus and then analysed using real-time RT-PCR. Levels of MMP1, MMP3 and MMP13 were significantly upregulated in infected bone samples compared to the sterile control; however, CTSK expression was unchanged (Fig. 7).

\section{In vitro osteocyte infection analysis}

To confirm that osteocytes specifically expressed bone-matrix-degrading enzymes in response to bacterial infection, the expression of the above genes was also examined in human primary osteocyte-like cultures with acute $S$. aureus infection. At the time of infection, these cells expressed the expected array of osteocyte markers including OCN, DMP1, FGF23, MEPE, PHEX, RANKL and SOST (Fig. 8a). Following a $2 \mathrm{~h}$ infection period and clearance of extracellular bacteria, conditions resulting in intracellular infection (Yang et al., 2018), mRNA levels were assayed by realtime RT-PCR $24 \mathrm{~h}$ later. Levels of MMP1, MMP13 and $M M P 3$ were strongly upregulated in the infected cultures compared to non-infected controls (Fig. $8 \mathbf{b}$-d). CTSK levels were not significantly altered by exposure to bacteria (Fig. 8e).

\section{Discussion}

Accelerated or extensive bone remodelling is a longrecognised feature of osteomyelitis. It has widely been assumed that the accelerated osteoclastic bone resorption coupled with rapid new bone formation is responsible for the histological appearance of infected bone. Both osteoblasts and osteoclasts - the cell types responsible for bone matrix formation and resorption, respectively - are cell targets for common bacterial pathogens in PJI, in particular $S$. aureus. In the present study, bone from the ACET of patients with hip PJI was compared with controls a

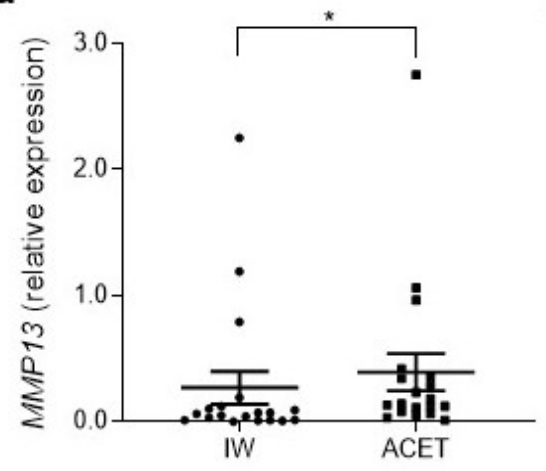

C

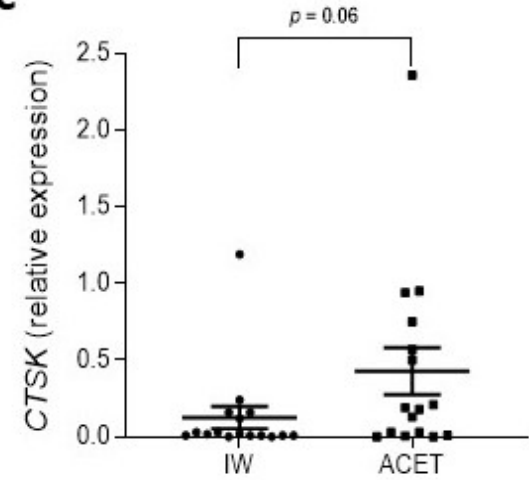

b

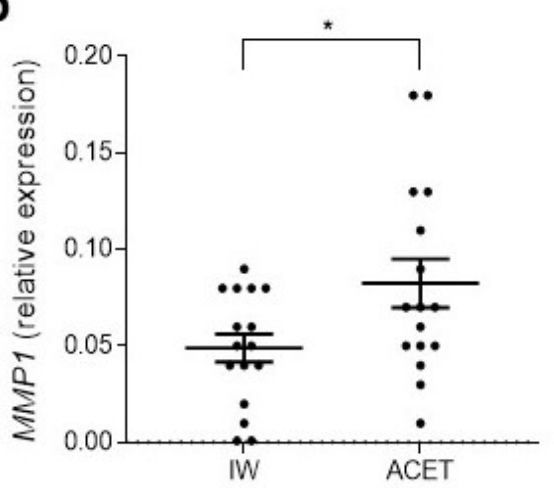

d

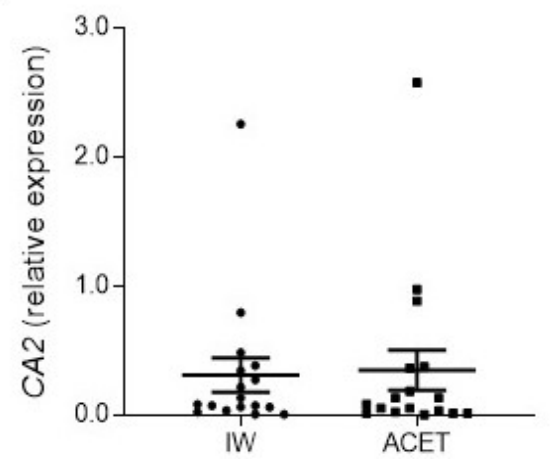

Fig. 5. Bone degradation marker expression in PJI bone. Real-time RT-PCR was performed from total RNA isolated from paired IW and acetabular bone biopsies taken from patients undergoing staged revision surgery for PJI. The expression of (a) MMP13, (b) MMP1, (c) CTSK and (d) CA2 was normalised to the expression of the housekeeping GAPDH. Data shown are mean expression \pm standard error of the mean. Significance (Wilcoxon matched-pairs test) is indicated by $*<0.05$. 
from either the IW of the same hip, distal from the infected region, or acetabular samples from patients undergoing a primary THR. PJI bone, as expected, was characterised by the increased presence of TRAP-positive osteoclasts, although this was not uniform between donors, with some PJI bone samples appearing indistinguishable from controls in this regard. However, osteoclasts are a relatively rare cell type in adult human bones so their detection may be highly dependent on the area of bone biopsied.

The histological appearance of the osteocyte network in toluidine-blue-stained sections, in terms of osteocyte lacuna area, was indistinguishable
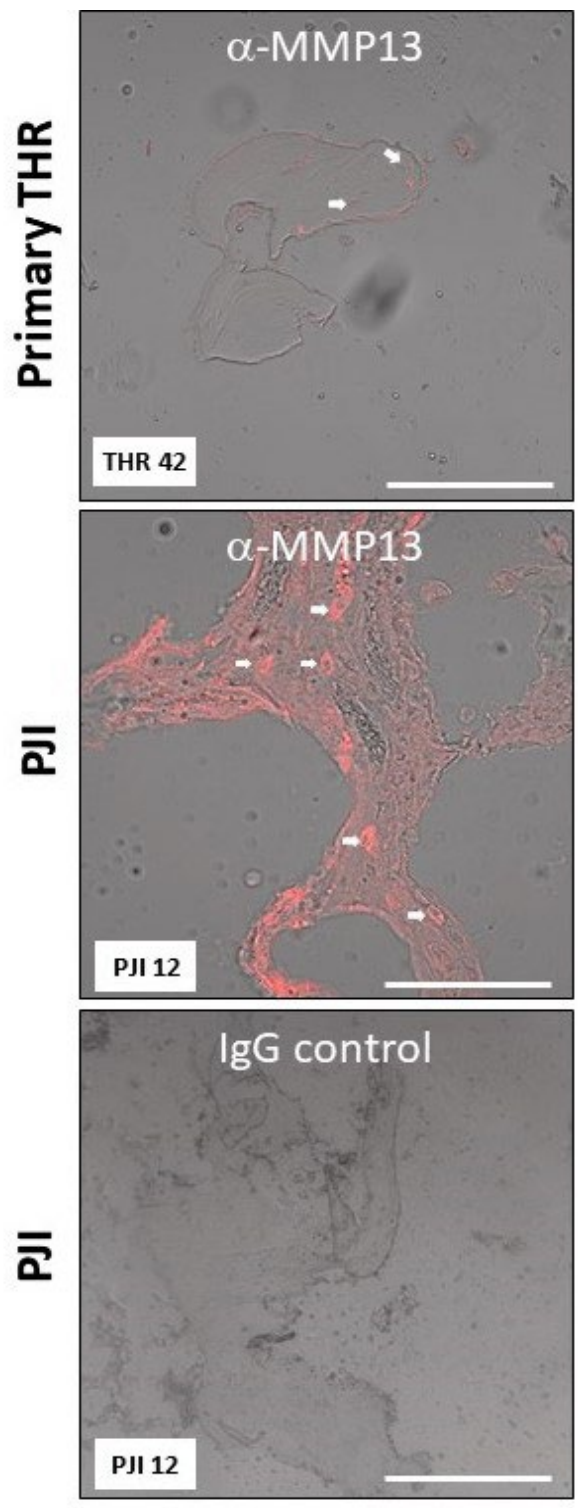

Fig. 6. Expression of MMP13 in patient bone. Bone sections were prepared from OCT-embedded acetabular bone that were immunostained using either anti-human MMP13 or isotype-matched negative control monoclonal antibodies and detected by immunofluorescence. White arrows denote examples of osteocyte lacunae. Underlying tissue is shown using differential interference contrast imaging on a confocal microscope (20× objective lens). Patient numbers are indicated. Scale bars: $100 \mu \mathrm{m}$. between PJI and primary THR control bone, and between the IW, distal to the infected joint, and the potentially infected acetabular region of a PJI bone. This was true for both male and female PJI patients. This suggested that the infection did not trigger the "classical pathway" of osteocytic osteolysis, which would be expected to result in measurably larger Ot.Lac.Ar (Atkins et al., 2009; Kogawa et al., 2013; Qing et al., 2012; Qing and Bonewald, 2009) and which is a feature of aseptic loosening in female patients (Ormsby et al., 2016; Ormsby et al., 2019a). In females, acetabular bone exhibited a higher osteocyte density than IW bone in both primary THR and PJI cohorts. However, PJI acetabular bone exhibited increased N.Ot/B.Ar and Ot.Lac.Ar/B.Ar. These latter increases were only observed in males, suggesting a gender difference based on bone remodelling rate. In future studies, it would be interesting to determine whether this affected treatment outcomes or indeed the incidence of PJI, which is increased in males (Yazdi et al., 2020).

Further histological investigation using Masson's trichrome staining of demineralised sections revealed the often-dramatic absence of mature or intact collagen within the trabeculae of a PJI bone, clearly surrounding the osteocyte lacunae. In many cases, there was evidence of apparently degraded collagen contiguous with lamellar structures of intact collagen, suggesting that this was degraded bone not woven bone, which lacks lamellae (Shapiro and $\mathrm{Wu}$,

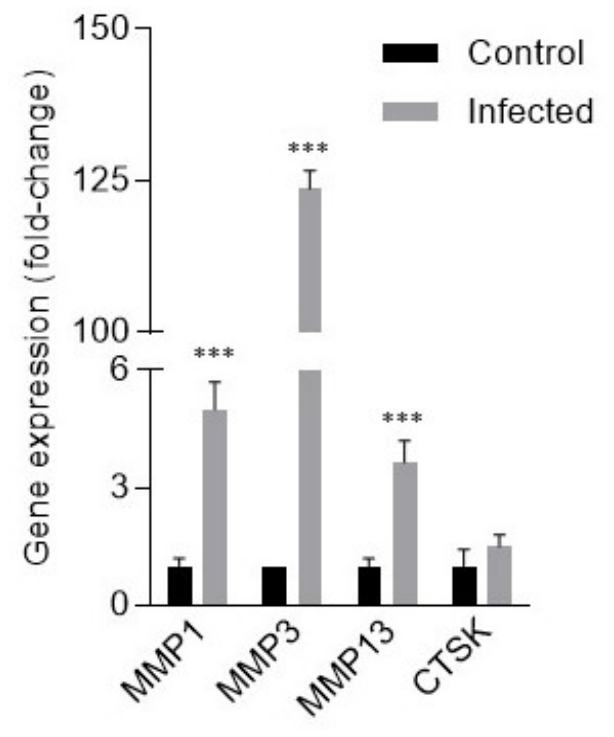

Fig. 7. Gene expression analysis of human bone exposed to $S$. aureus. Human cancellous bone fragments were cultured ex vivo in the absence (control) or presence of $S$. aureus strain WCH-SK2. Real-time RT-PCR was performed for the expression of MMP1, MMP3, MMP13 and CTSK normalised to that of GAPDH and expressed as fold-change relative to control. Data shown are means \pm standard error of the mean of biological triplicates, each with technical duplicates. Significant difference (two-way ANOVA) to expression in non-exposed control bone is indicated by ${ }^{* * *} p<0.001$. 
2019). However, certain patient samples did contain evidence of woven bone. Coupled with SHG analysis, it was possible to conclude that mature bone matrix could be degraded within bony trabeculae in PJI, perhaps in an attempt by the osteocytes to remodel the fibrillar structure. This histological feature was apparent in all PJI cases examined and, therefore, was independent of the pathogen identified, occurring in patients with a range of Gram-positive and Gramnegative bacteria. Furthermore, this feature was found irrespective of whether the bone was sampled at the first- or second-stage revision THR operation, procedures that occurred in this patient cohort at an interval of around 3 months. This suggested that the bone matrix degradation or remodelling induced by infection was slow to resolve. As such, bone matrix collagen degradation or turnover in PJI bone biopsies may be a useful adjunct indicator of either an active or an historical infection. It is possible that quantification of this process from histological sections, as performed in the present study, may prove useful in deciding for borderline cases, although a thorough comparison with other inflammatory pathologies will be necessary to establish this.

S. aureus is known to produce several exotoxins, such as Aur and the staphopains (in particular SspB), that enzymatically cleave collagen and can contribute to host tissue damage (Lehman et al.,

a

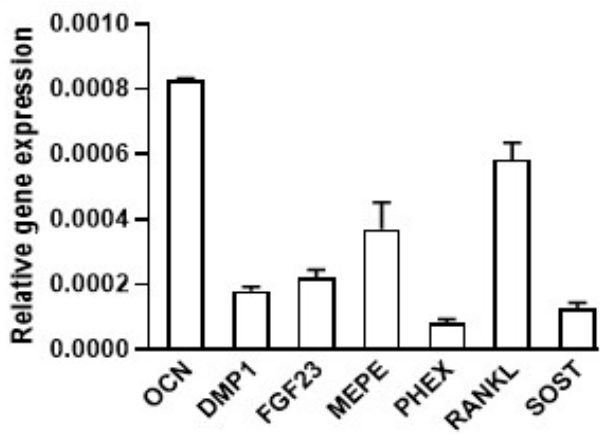

b

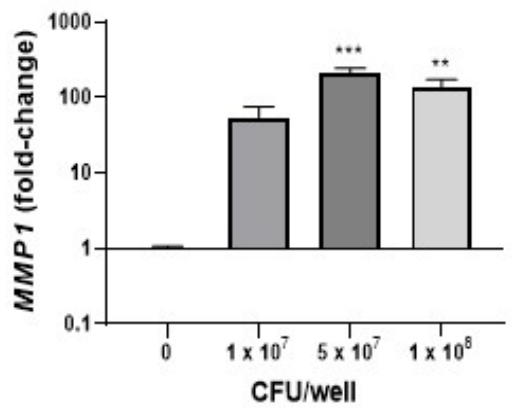

d

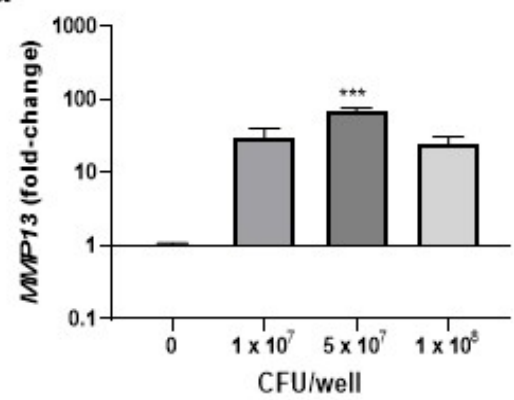

C

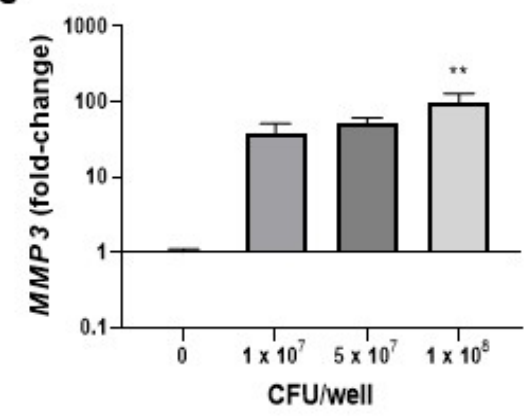

e

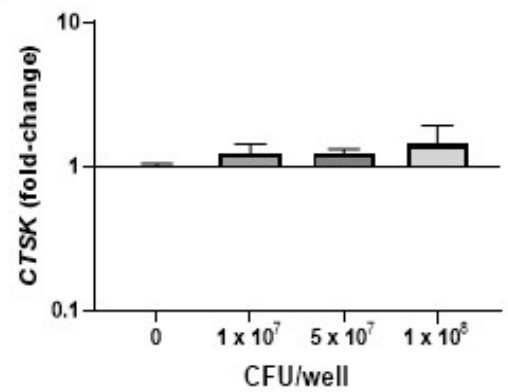

Fig. 8. Gene expression analysis of human osteocyte-like cultures exposed to S. aureus. Human-bonederived cells were differentiated into a mature osteocyte-like stage, (a) which was confirmed by realtime RT-PCR results at the $28 \mathrm{~d}$ time point (through expression of a panel of known osteocyte markers). Differentiated cells were further cultured in vitro in the absence or presence of $S$. aureus strain WCH-SK2 added at $1 \times 10^{7}, 5 \times 10^{7}$ or $1 \times 10^{8} \mathrm{CFU} /$ well. Real-time RT-PCR was performed to measure the expression of (b) MMP1, (c) MMP3, (d) MMP13 and (e) CTSK, normalised to that of BACT and expressed as foldchange relative to control (no added bacteria). Data shown are means \pm standard error of the mean of biological triplicates, each with technical duplicates, and are representative of experiments performed with 3 independent donors' cells. Significant difference to expression in non-exposed control cells was calculated using one-way ANOVA with Dunnett's multiple comparison post-hoc tests and is indicated by ** $p<0.01$ and ${ }^{* * *} p<0.001$. 
2019; Ohbayashi et al., 2011; Tam and Torres, 2019). However, coagulase-negative staphylococci, such as Staphylococcus epidermidis and S. warneri, as well as non-staphylococcal bacteria Acinetobacter, $P$. aeruginosa and $C$. acnes, causative pathogens that were identified in one or more patients in the present study, are not known to express these or similar enzymes. Thus, a likely cause of collagen degradation in PJI bone is host-cell-derived collagenase activity. Consistent with this concept, PJI samples from the ACET expressed significantly more MMP1 and MMP13 than control IW bone. Immunostaining revealed strong expression of MMP13 by resident osteocytes. Osteocytic expression of MMP13 during perilacunar remodelling has been shown to be critical for maintaining bone matrix integrity in rodent models (Tang et al., 2012). The increase in MMP expression could be a consequence of the systemic immune response to the pathogen or possibly a direct response of bone-resident cells to the invading bacteria. Using an ex vivo bone infection model, $S$. aureus caused the acute upregulation of MMP1, MMP3 and MMP13 expression, arguing for the latter. Furthermore, acute exposure of primary osteocyte-like cultures to $S$. aureus caused the profound induction of expression of these MMPs. Overall, these findings are consistent with bacterial induction of bone-matrix-degrading enzyme expression in osteocytes in PJI, contributing to bone matrix breakdown or remodelling. It has long been suggested that osteocytic osteolysis occurs as a prelude to or in concert with bone resorption by osteoclasts(Parfitt, 1977; Tsourdi et al., 2013) and the form of matrix removal by osteocytes evident in the present study may also reflect these functions. However, osteoclasts, while numerous in some cases, were not always present in the bone sections assayed.

The release of MMPs by infected osteocytes suggested that this was a previously unrecognised function of the innate immune response attempting to clear the infected tissue of either infected cells or pathogens. For example, the neutrophil protease cathepsin $\mathrm{G}$ has been shown to activate MMP1 during bacterial infection leading to promotion of tissue degradation. A single nucleotide polymorphism in CTSG, associated with reduced MMP1 levels, is more frequent in patients with osteomyelitis (PérezIs et al., 2019). However, a polymorphism in MMP1, also more frequent in osteomyelitis patients, leads to increased MMP1 levels (Montes et al., 2010). Thus, it is not clear if elevated bone MMP expression in osteomyelitis and PJI is an advantage to the patient. Indeed, bone-matrix degradation by the osteocyte may be detrimental to the host, as it could cause further spreading of bacteria, allowing access to more deeply buried osteocytes - which are less accessible to immune cells - and overall providing further opportunities for the pathogen to establish a niche contributing to a chronic infection.

It remains to be seen if the processes identified in the present study can be captured in situ by any of the currently used or emerging patient imagingmodalities. In a recent review, the relative merits of these and the recommendations of the Third European Congress on Inflammation/Infection Imaging have been discussed (Romanò et al., 2020). CT or MRI show encouraging utility for PJI diagnosis in terms of identifying oedema, periosteal changes and macroscopical bone-lesions. It would be of interest to correlate imaging features using these modalities as well as others that identify more localised features of bone remodelling, such as bone scintigraphy, with the histological findings described in the present study where biopsies were taken intra-operatively based on gross appearance. It is possible that techniques such as CT or ultrasound could be used to enhance bone biopsy retrieval in combination with the histological processes described in the present study; however, this remains to be explored.

In summary, the present study identified that loss or absence of mature bone matrix collagen is a feature of human PJI and suggested that this was related to the pathological induction of MMP expression in response to invading bacteria by bone resident cells, including osteocytes. Histological detection of this process using Masson's trichrome or a similar staining technique for bone collagen integrity may prove to be a useful adjunct indicator of past or present infection in the diagnosis of PJI and potentially other forms of osteomyelitis.

\section{Acknowledgements}

The study received funding from the National Health and Medical Research Council of Australia (NHMRC) (Grant number 1106029) and the Australian Orthopaedic Association (Grant ID96). The authors have no competing interests to declare.

\section{References}

Ahmed S, Meghji S, Williams RJ, Henderson B, Brock JH, Nair SP (2001) Staphylococcus aureus fibronectin binding proteins are essential for internalization by osteoblasts but do not account for differences in intracellular levels of bacteria. Infect Immun 69: 2872-2877.

Anemuller R, Belden K, Brause B, Citak M, Del Pozo JL, Frommelt L, Gehrke T, Hewlett A, Higuera CA, Hughes H, Kheir M, Kim KI, Konan S, Lausmann C, Marculescu C, Morata L, Ramirez I, Rossmann M, Silibovsky R, Soriano A, Suh GA, Vogely C, Volpin A, Yombi J, Zahar A, Zimmerli W (2019) Hip and knee section, treatment, antimicrobials: proceedings of international consensus on orthopedic infections. J Arthroplasty 34: S463-S475.

Atkins GJ, Anderson PH, Findlay DM, Welldon KJ, Vincent C, Zannettino AC, O'Loughlin PD, Morris 
HA (2007) Metabolism of vitamin D3 in human osteoblasts: evidence for autocrine and paracrine activities of 1 alpha,25-dihydroxyvitamin D3. Bone 40: 1517-1528.

Atkins GJ, Rowe PS, Lim HP, Welldon KJ, Ormsby R, Wijenayaka AR, Zelenchuk L, Evdokiou A, Findlay DM (2011) Sclerostin is a locally acting regulator of late-osteoblast/preosteocyte differentiation and regulates mineralization through a MEPE-ASARMdependent mechanism. J Bone Miner Res 26: 14251436.

Atkins GJ, Welldon KJ, Holding CA, Haynes DR, Howie DW, Findlay DM (2009) The induction of a catabolic phenotype in human primary osteoblasts and osteocytes by polyethylene particles. Biomaterials 30: 3672-3681.

Barragan-Adjemian C, Nicolella D, Dusevich V, Dallas MR, Eick JD, Bonewald LF (2006) Mechanism by which MLO-A5 late osteoblasts/early osteocytes mineralize in culture: similarities with mineralization of lamellar bone. Calcif Tissue Int 79: 340-353.

Bui LM, Hoffmann P, Turnidge JD, Zilm PS, Kidd SP (2015) Prolonged growth of a clinical Staphylococcus aureus strain selects for a stable small-colony-variant cell type. Infect Immun 83: 470-481.

Campagnola PJ, Millard AC, Terasaki M, Hoppe PE, Malone CJ, Mohler WA (2002) Three-dimensional high-resolution second-harmonic generation imaging of endogenous structural proteins in biological tissues. Biophys J 82: 493-508.

Claro T, Widaa A, O'Seaghdha M, Miajlovic H, Foster TJ, O'Brien FJ, Kerrigan SW (2011) Staphylococcus aureus protein a binds to osteoblasts and triggers signals that weaken bone in osteomyelitis. PLoS One 6: e18748. DOI: 10.1371/journal.pone.0018748.

de Mesy Bentley KL, MacDonald A, Schwarz EM, Oh I (2018) Chronic osteomyelitis with Staphylococcus aureus deformation in submicron canaliculi of osteocytes: a case report. JBJS Case Connect 8: e8. DOI: 10.2106/JBJS.CC.17.00154.

de Mesy Bentley KL, Trombetta R, Nishitani K, Bello-Irizarry SN, Ninomiya $\mathrm{M}$, Zhang L, Chung HL, McGrath JL, Daiss JL, Awad HA, Kates SL, Schwarz EM (2017) Evidence of Staphylococcus aureus deformation, proliferation, and migration in canaliculi of live cortical bone in murine models of osteomyelitis. J Bone Miner Res 32: 985-990.

George J, Navale SM, Nageeb EM, Curtis GL, Klika AK, Barsoum WK, Mont MA, Higuera CA (2018) Etiology of above-knee amputations in the United States: is periprosthetic joint infection an emerging cause? Clin Orthop Relat Res 476: 1951-1960.

Hofstee MI, Muthukrishnan G, Atkins GJ, Riool M, Thompson K, Morgenstern M, Stoddart MJ, Richards RG, Zaat SAJ, Moriarty TF (2020) Current concepts of osteomyelitis: from pathologic mechanisms to advanced research methods. Am J Pathol 190: 11511163.

Ito $\mathrm{N}$, Wijenayaka AR, Prideaux M, Kogawa $\mathrm{M}$, Ormsby RT, Evdokiou A, Bonewald LF, Findlay DM,
Atkins GJ (2015) Regulation of FGF23 expression in IDG-SW3 osteocytes and human bone by proinflammatory stimuli. Mol Cell Endocrinol 399: 208218.

Kapadia BH, Banerjee S, Cherian JJ, Bozic KJ, Mont MA (2016) The economic impact of periprosthetic infections after total hip arthroplasty at a specialized tertiary-care center. J Arthroplasty 31: 1422-1426.

Khan N, Parmar D, Ibrahim MS, Kayani B, Haddad FS (2019) Outcomes of repeat two-stage exchange hip arthroplasty for prosthetic joint infection. Bone Joint J 101-B: 110-115.

Kogawa M, Findlay DM, Anderson PH, Ormsby R, Vincent C, Morris HA, Atkins GJ (2010) Osteoclastic metabolism of $25(\mathrm{OH})$-vitamin D3: a potential mechanism for optimization of bone resorption. Endocrinology 151: 4613-4625.

Kogawa M, Khalid KA, Wijenayaka AR, Ormsby RT, Evdokiou A, Anderson PH, Findlay DM, Atkins GJ (2018) Recombinant sclerostin antagonizes effects of ex vivo mechanical loading in trabecular bone and increases osteocyte lacunar size. Am J Physiol Cell Physiol 314: C53-C61.

Kogawa M, Wijenayaka AR, Ormsby RT, Thomas GP, Anderson PH, Bonewald LF, Findlay DM, Atkins GJ (2013) Sclerostin regulates release of bone mineral by osteocytes by induction of carbonic anhydrase 2 . J Bone Miner Res 28: 2436-2448.

Lehman MK, Nuxoll AS, Yamada KJ, Kielian T, Carson SD, Fey PD (2019) Protease-mediated growth of Staphylococcus aureus on host proteins is opp3 dependent. mBio 10: e02553-18. DOI: 10.1128/ mBio.02553-18.

Livak KJ, Schmittgen TD (2001) Analysis of relative gene expression data using real-time quantitative PCR and the 2(-Delta Delta C(T)) method. Methods 25: 402-408.

Lotinun S, Ishihara Y, Nagano K, Kiviranta R, Carpentier VT, Neff L, Parkman V, Ide N, Hu D, Dann P, Brooks D, Bouxsein ML, Wysolmerski J, Gori F, Baron R (2019) Cathepsin K-deficient osteocytes prevent lactation-induced bone loss and parathyroid hormone suppression. J Clin Invest 129: 3058-3071.

Montes AH, Valle-Garay E, Alvarez V, Pevida M, García Pérez E, Paz J, Meana A, Asensi V (2010) A functional polymorphism in MMP1 could influence osteomyelitis development. J Bone Miner Res 25: 912-919.

Nadiarnykh O, Plotnikov S, Mohler WA, Kalajzic I, Redford-Badwal D, Campagnola PJ (2007) Second harmonic generation imaging microscopy studies of osteogenesis imperfecta. J Biomed Opt 12: 051805. DOI: 10.1117/1.2799538.

O'Brien CA, Nakashima T, Takayanagi H (2013) Osteocyte control of osteoclastogenesis. Bone 54: 258263.

Ohbayashi T, Irie A, Murakami Y, Nowak M, Potempa J, Nishimura $Y$, Shinohara M, Imamura $T$ (2011) Degradation of fibrinogen and collagen by staphopains, cysteine proteases released from 
Staphylococcus aureus. Microbiology (Reading) 157: 786-792.

Ong KL, Kurtz SM, Lau E, Bozic KJ, Berry DJ, Parvizi J (2009) Prosthetic joint infection risk after total hip arthroplasty in the medicare population. J Arthroplasty 24: 105-109.

Ormsby RT, Cantley M, Kogawa M, Solomon LB, Haynes DR, Findlay DM, Atkins GJ (2016) Evidence that osteocyte perilacunar remodelling contributes to polyethylene wear particle induced osteolysis. Acta Biomater 33: 242-251.

Ormsby RT, Solomon LB, Stamenkov R, Findlay DM, Atkins GJ (2019a) Evidence for gender-specific bone loss mechanisms in periprosthetic osteolysis. J Clin Med 9: 53. DOI: 10.3390/jcm9010053.

Ormsby RT, Solomon LB, Yang D, Crotti TN, Haynes DR, Findlay DM, Atkins GJ (2019b) Osteocytes respond to particles of clinically-relevant conventional and cross-linked polyethylene and metal alloys by up-regulation of resorptive and inflammatory pathways. Acta Biomater 87: 296-306.

Parfitt AM (1977) The cellular basis of bone turnover and bone loss: a rebuttal of the osteocytic resorption-bone flow theory. Clin Orthop Relat Res 127: 236-247.

Parvizi J, Tan TL, Goswami K, Higuera C, Della Valle C, Chen AF, Shohat N (2018) The 2018 definition of periprosthetic hip and knee infection: an evidencebased and validated criteria. J Arthroplasty 33: 13091314.

Pérez-Is L, Ocaña MG, Montes AH, Carton JA, Álvarez V, Meana Á, Fierer J, Valle-Garay E, Asensi $\mathrm{V}$ (2019) The N125S polymorphism in the cathepsin G gene (rs45567233) is associated with susceptibility to osteomyelitis in a Spanish population. PLoS One 14: e0220022. DOI: 10.1371/journal.pone.0220022.

Ponce MC, Zorzi AR, Miranda JB, Amstalden EMI (2018) Proposal for a new histological scoring system for cartilage repair. Clinics (Sao Paulo) 73: e562. DOI: 10.6061/clinics/2018/e562.

Prideaux M, Findlay DM, Atkins GJ (2016) Osteocytes: the master cells in bone remodelling. Curr Opin Pharmacol 28: 24-30.

Proctor RA, von Eiff C, Kahl BC, Becker K, McNamara P, Herrmann M, Peters G (2006) Small colony variants: a pathogenic form of bacteria that facilitates persistent and recurrent infections. Nat Rev Microbiol 4: 295-305.

Qing H, Ardeshirpour L, Pajevic PD, Dusevich V, Jähn K, Kato S, Wysolmerski J, Bonewald LF (2012) Demonstration of osteocytic perilacunar/canalicular remodeling in mice during lactation. J Bone Miner Res 27: 1018-1029.

Qing H, Bonewald LF (2009) Osteocyte remodeling of the perilacunar and pericanalicular matrix. Int J Oral Sci 1: 59-65.

Romanò CL, Petrosillo N, Argento G, Sconfienza LM, Treglia G, Alavi A, Glaudemans A, Gheysens O, Maes A, Lauri C, Palestro CJ, Signore A (2020) The role of imaging techniques to define a peri-prosthetic hip and knee joint infection: multidisciplinary consensus statements. J Clin Med 9: 2548. DOI: $10.3390 /$ jcm 9082548 .

Ryan JW, Starczak Y, Tsangari H, Sawyer RK, Davey RA, Atkins GJ, Morris HA, Anderson PH (2016) Sex-related differences in the skeletal phenotype of aged vitamin D receptor global knockout mice. J Steroid Biochem Mol Biol 164: 361-368.

Shahi A, Tan TL, Chen AF, Maltenfort MG, Parvizi J (2017) In-hospital mortality in patients with periprosthetic joint infection. J Arthroplasty 32: 948952.

Shapiro F, Wu JY (2019) Woven bone overview: structural classification based on its integral role in developmental, repair and pathological bone formation throughout vertebrate groups. Eur Cell Mater 38: 137-167.

Tam K, Torres VJ (2019) Staphylococcus aureus secreted toxins and extracellular enzymes. Microbiol Spectr 7: 10.1128/microbiolspec.GPP3-0039-2018.DOI: 10.1128/microbiolspec.GPP3-0039-2018.

Tang SY, Herber RP, Ho SP, Alliston T (2012) Matrix metalloproteinase-13 is required for osteocytic perilacunar remodeling and maintains bone fracture resistance. J Bone Miner Res 27: 1936-1950.

Tsourdi E, Jähn K, Rauner M, Busse B, Bonewald LF (2018) Physiological and pathological osteocytic osteolysis. J Musculoskelet Neuronal Interact 18: 292303.

Tucker KA, Reilly SS, Leslie CS, Hudson MC (2000) Intracellular Staphylococcus aureus induces apoptosis in mouse osteoblasts. FEMS Microbiol Lett 186: $151-156$.

Welldon KJ, Findlay DM, Evdokiou A, Ormsby RT, Atkins GJ (2013) Calcium induces pro-anabolic effects on human primary osteoblasts associated with acquisition of mature osteocyte markers. Mol Cell Endocrinol 376: 85-92.

Wijenayaka AR, Kogawa M, Lim HP, Bonewald LF, Findlay DM, Atkins GJ (2011) Sclerostin stimulates osteocyte support of osteoclast activity by a RANKLdependent pathway. PLoS One 6: e25900. DOI: 10.1371/journal.pone.0025900.

Yang D, Wijenayaka AR, Solomon LB, Pederson SM, Findlay DM, Kidd SP, Atkins GJ (2018) Novel insights into Staphylococcus aureus deep bone infections: the involvement of osteocytes. mBio 9: e00415-18. DOI: 10.1128/mBio.00415-18.

Yazdi H, Restrepo C, Foltz C, Hammad M, Chung PH, Gomella LG, Parvizi J (2020) Symptomatic benign prostatic hyperplasia: a risk factor for periprosthetic joint infection in male patients. J Bone Joint Surg Am 102: 543-549.

\section{Web Reference}

1. Registry AOANJR (2017) Australian orthopaedic association national joint replacement registry annual report. https://aoanjrr.sahmri.com/annualreports-2017 [29.09-2021] 


\section{Discussion with Reviewers}

Reviewer 1: Do you plan to compare the results obtained from the analyses of collagen fibrillar structure in PJI patients with other inflammatory pathologies?

Authors: Yes, we consider this to be critical for gauging the clinical utility of our findings. We plan to examine collagen structure in THR patients revised for aseptic loosening and other inflammatory pathologies, such as rheumatoid arthritis.

Reviewer 1: The authors suggested that matrix degradation is manly connected to osteocytic osteolysis. However, MMPs are also expressed in other cell types and are important regulators in the bone turnover that is orchestrated by several cells and cytokines. Do you plan to investigate the relationship between different bone-related cell types and the several MMPs involved in bone-matrix degradation? Authors: We agree that MMPs are widely expressed and we do not mean to claim that MMPs are only connected to osteocytic osteolysis. Rather, we present evidence that they are expressed in whole bone tissue from PJI patients and there is good evidence that this is due to expression by osteocytes in the context of infection. We think that the dramatic loss of the collagenous bone matrix described in the present study, in the absence of lacunae enlargement, is different from the "classical" osteocytic osteolysis, which has been described as a reversible process involving perilacunar and/or peri-canalicular loss of bone, resulting in enlargement of these micro- porosities. As noted, this physiological process occurs pathologically in the response to wear particles in the context of aseptic loosening (Ormsby et al., 2016, 2019a and 2019b) but this is different from the process occurring in PJI. It will certainly be of interest to study the contributions of other cell types in this context, however the observation that deeply buried osteocytes contribute to bone loss "from within" in PJI has exciting new implications for the role these cells play in the immune response to infection.

Reviewer 2: How would you expect aseptic loosening to appear when subjected to such investigations?

Authors: In terms of osteoclasts, we would expect TRAP-staining of aseptic loosening bone to reveal a similar pattern to the PJI samples, although in these cases osteoclasts are perhaps a rarer cell type than in PJI (Ormsby et al., 2016). With respect to osteocytes, published studies of aseptic loosening patient bone stained with toluidine blue (Ormsby et al., 2019a and $2019 b$ ) showed that (only in female patients) osteocyte lacunae are enlarged in a more "classical" osteocytic osteolysis pattern, while no changes to the lacunar size were observed in the present study. We are yet to perform and analyse Masson's trichrome analysis for collagen structure in aseptic loosening bone or in other inflammatory pathologies, such as rheumatoid arthritis, but this will be a very interesting study to perform and we hope to do so in the near future.

Editor's note: The Scientific Editor responsible for this paper was Fintan Moriarty. 